\title{
Incidence and Phenotypic Characterization of Staphylococcus Aureus Isolated from Mastitic Cows
}

A.A.Abd El-Tawab' ${ }^{1}$, A.M.Ammar ${ }^{2}$, F.I.Hofy ${ }^{1}$, S.R.Mohamed ${ }^{3}$, H.S.Abubakr ${ }^{3}$

${ }^{1}$ Bacteriology, Immunology and Mycology Dept., Faculty of Veterinary Medicine, Benha Univ., Egypt

${ }^{2}$ Bacteriology, Immunology and Mycology Dept., Faculty of VeterinaryMedicine, Zagazig Univ., Egypt

${ }^{3}$ Animal Health Research Institute(Dokki branch), Egypt

\begin{abstract}
A total of 412 milk samples were collected from clinically and subclinical mastitic cows $(188,224)$ respectively and examined bacteriologically for Staphylococcus aureus for the isolation rate and studying of the phenotypic characterization of the isolates. The results revealed that S.aureus was isolated in an incidence of $50 \%$ and $17.5 \%$ from clinically mastitic and subclinically mastitic cows respectively. All Staphylococcus isolates showed symmetrically in their phenotypic characterization including cultural characters on different media. Vitek2 system succeeded in providing definitive identification results for gram positive bacterial by identification card (GP) were used for rapid and easy identification of Staphylococcus spp .
\end{abstract}

Keywords : Saureus, Clinical, Subclinical, Mastitis-Vitek2.

\section{Introduction}

Mastitis (inflammation of mammary gland) is one of the most devastating disease conditions leading to significant economic losses globally [1]; because of reduced milk production, treatment costs, increased labor, milk withholding following treatment, death and premature culling Due to multiple etiologies, it always remained a challenge to veterinarian worldwide. Approximately, 140 species of microorganisms have been identified as etiological agents of bovine mastitis. Of these various etiological agents, Staphylococcus aureus is a major pathogen associated with bovine clinical and subclinical mastitis $[2,3,4,5]$.

The mastitis caused by $S$. aureus is characterized by significantly lower cure rates compared with infections caused by other microorganisms, which may be either as a result of unusually frequent acquisition of antibiotic resistance mechanisms among this group of bacteria or also their ability to form biofilm (slime) [6]. Considering the potential of the area and the economic significance of dairy production to the local community.

Almost any microbe that can opportunistically invade tissue and cause infection can cause mastitis. About 150 species of microorganisms mostly bacterial is able to cause mastitis.[7]However, staphylococci, streptococci and other related gram-positive, catalase-negative cocci represent the most important causative agents.[8]

Staphylococcus species are aerobically growing Gram-positive cocci . Isolation of Staphylococcus species is usually not difficult since Staphylococci not fastidious organism and will grow on commonly media and under variety of conditions[9]

Mastitis is recognized as the most important dairy herd problems worldwide. Economic losses of mastitis include decrease in milk quantity \& quality and high cost of treatment Staphylococcus aureus is one of the most common etiological pathogens, causing intramammary infections in dairy herds leading to severe economic losses in worldwide industry. Accurate identification of the Staphylococcus aureus is therefor of great importance in bacteriological laboratory, The vitek2 system used with gram positive (GP) identification card [10] is an automated machine designed to provide rapid and accurate phenotypic identification for most clinical staphylococcus . [11] the present study was carried out to detect the incidence of Staphylococcus aureus infection in mastitis cases and their phenotypic characterization.

Recently a new automated identification system such as Vitek2, accompanied by identification cards that give reliable and rapid identification, was internationally reported by[12]. In addition, identification of bacteria by VITEK2 system has revealed prominent inter laboratory reproducibility and is quickly being included as a routine method for animal laboratory microbiology .

\section{Material and methods}

\subsection{Animals}

A total of 103 cows were examined in this study were classified into clinical and subclinical mastitic cases as (47) clinically mastitic cows and (56) subclinically mastitic cows.

\subsection{Samples}

A total of 412 milk samples of which 188 from clinically infected cases and collected according to[[13].The udder of each animal was palpated before sampling for presence of clinical signs of mastitis, the examined udders were thoroughly washed and carefully dried with clean dry towel. Then the teat was swabbed with $70 \%$ ethyl alcohol. After that the first few jets of milk were discarded and milk samples were collected in $50 \mathrm{ml}$ sterile falcon tube from clinically affected quarter. As well as 224 milk samples were collected from subclinical infected cows (Normal milk) after 
application of California mastitis test (CMT) according to[14]

Clinical examination : The cases of Clinical Mastitis (CM) were diagnosed on the basis of history, clinical signs, physical examination of udder (swelling and pain) and milk (colour-yellow or blood tinged and consistency-watery, etc), while subclinical mastitis (SCM) was diagnosed on the basis of California Mastitis Test (CMT) [15].

Bacterial isolation and identification: Each of the thoroughly mixed milk sampler(Mastitis/subclinical mastitis) was transferred to $10 \mathrm{~mL}$ of nutrient broth and incubated at $37^{\circ} \mathrm{C}$ for $15-18 \mathrm{~h}$ to resuscitate the organisms. Thereafter, a loopful of inoculum from the nutrient broth was streaked on to nutrient agar plates and incubated at $37^{\circ} \mathrm{C}$ for $24 \mathrm{~h}$. Presumptive Staphylococcus colonies (golden/white, round, smooth, glistening, opaque) were picked up and characterized biochemically as[16]. Identification by Vitek 2 compact system and gram positive test (GP card) were doneaccording to the manufacture' sinstruction[12]

\section{Results \\ 3.1 Isolation and identification of microbe 3.1.1 Morphological identification}

Out of 188 milk samples of clinically bovine mastitis 94isolates with incidence $(50 \%)$ and out of 224 subclinical mastitis 39 isolates with incidence $(17.5 \%)$ were positive for Staphylococcus

\subsubsection{Cultural characteristics}

After aerobic incubation on nutrient agar, mannitol salt agar for 24-48 hours at $37 \mathrm{C}^{\circ}$, colonies suspected as Staphylococcus were large, 1$3 \mathrm{~mm}$ in diameter, and well isolated colonies reached $4 \mathrm{~mm}$ in diameter. The suspected colonies were round, convex, smooth with glistening surface. After aerobic incubation of 33 isolates on Baired-Parker's agar media for 24-48 hours at 37 $\mathrm{C}^{\circ}, 10$ isolates $(30.3 \%)$ produced black, shiny, convex colonies with entire margins and clear zone surrounding the colonies with or without an opaque zone. This result confirmed by biochemical identification of 33 suspected Staphylococcus isolates that they were 10 isolates $(30.3 \%)$ were positive for Catalase test (slide technique), Oxidase test, Oxidation - fermentation of glucose (O-F test), Urease test, Gelatin liquefaction test, Mannitol fermentation test, Coagulase test and showed Bhemolysis on Nutrient agar containing $7.5 \% \mathrm{NaCl}$ and $5 \%(\mathrm{~V} / \mathrm{V})$ defibrinated sheep blood was used.

\section{Discussion}

Among 34 samples, 12 (32.29\%) showed Bhemolysis on $5 \%$ cattle blood agar with circular, small, smooth raised whitish colony.[17] reported that $89.3 \%$ S. aureus from bovine origin were hemolytic. This variation was due to the difference in sample origin indicating that raw milk contained less association with $S$. aureus as compared with feces of cattle from where the bacteria were isolated by them. After overnight incubation on MS agar media, some plates showed yellow colony and some plates showed whitish colony. All the suspected $S$. aureus which produced B- hemolysis on $5 \%$ blood agar were able to ferment mannitol salt agar characterized by the formation of yellow colony and white/transparent colony indicated other Staphylococcus spp., as indicated by[18] and[19]. In Gram staining, the organism revealed as Gram positive, violet colored, cocci shaped and arranged in grapes like cluster under light microscope.

In this study, Staphylococcus cultural characteristics on nutrient agar, white, yellow or orange water insoluble pigments were formed. And on mannitol salt agar,yellow or golden yellow water insoluble pigments were formed.Also they were aerobic and facultative, liquefied gelatin and fermented a number of carbohydrates to acid. These results were agreed with [20]. Staphylococcus cultural characteristics on Baired-Parker's agar media for $24-48$ hours at $37 \mathrm{C}^{\circ}$, produced black, shiny, convex colonies with entire margins and clear zones surrounding the colonies with or without an opaque zone. These results were agreed with that of[21] and[22].

The incidence of Staphylococcus aureus in clinical and subclinical mastitis were shown in Table (1) Overall incidence of Staphylococcus aureus in clinical as well as sub clinical mastitis, was $94 \%$ isolates out of 188 and $39 \%$ out of 224 respectively. The incidence of Staphylococcus aureus was higher $(50.00 \%)$ in clinical mastitis in comparison to that of subclinical mastitis $(17.50 \%)$ and the incidences of Staphylococcus aureus in clinical as well as sub-clinical mastitis were higher. These results are almost in the concurrence of previous study conducted in the region in 2010, which revealed $S$. aureus as a major pathogen in the cases of mastitis in Mathura and its surroundings. The incidence of S. aureus was $37.03 \%$ and $31.70 \%$ in cattle (1)It clearly indicated the presence of $S$. aureus as most prevailing pathogen in the cases of mastitis in dairy animals. Moreover, it is persisting in the similar pattern not only in clinical cases but also in subclinical cases. Various studies have been conducted in different parts of country to assess the prevalence status of bacterial pathogens in mastitis of dairy animals. Similar to the present findings, [23] also reported the staphylococcal mastitis in cows to be $31.94 \%$ while[24], [25] and[26], reported the incidence to be comparatively as $27.37 \%$ in Jharkhand, $27.1 \%$ and $21.0 \%$, respectively. However, higher incidence of staphylococcal mastitis was reported by [27,28,29] who reported the incidence of staphylococcal mastitis in cows to be $45 \%, 44 \%$ and $47.06 \%$ respectively. The high 
prevalence of staphylococci has been reported by several researchers [30,31] and [32,2, 3,34]. All Staphylococcus aureus isolates Table(1) were found catalase positive, oxidase negative urease positive, failed to grow on Macconkey agar, Voges Proskauer (VP) positive and coagulase positive on being subjected to above mentioned biochemical tests.

Similarly, previous studies conducted by[35] and[29] also reported high percentage positivity of S. aureus for coagulase production i.e. $100.00 \%$, where as lower percent positivity of $S$. aureus for coagulase production were also reported earlier by[36]34.50\%,[37] $50.00 \%$ and[28] $51.11 \%$. The presence of $100 \%$ coagulase positive isolates in present study further suggests the increase in the number of pathogenic $S$. aureus in dairy animals. This is an alarming condition as in general $S$. aureus are supposed to be non pathogenic commensal organisms.

Staphylococcus aureus is the most important bacterial microorganism in bovines causing contagious mastitis and highly economic losses in dairy herds [38]

In the present study bacteriological examination and identification of Staphylococcus aureus were depend on gram stain, culturing on Baired parker medium, catalase test, Coagulase tube test and DNase test.
This agreed with [39] they revealed that S.aureus is responsible for about $30 \%$ to $40 \%$ of all mastitis cases. This high prevalence of S.aureus in this study may be explained that transmission of infection occurs during the milking process by milker's hands, contaminated equipments and milking machine [40].

identification by Vitek 2 accompanied by Gram positive card is based on established biochemical methods and newly developed substrates measuring carbon source utilization enzymatic activities and resistance. There are 47 biochemical tests and one negative control well; Final results are available in approximately 10 hours or less (Biomerieux user guide, 2006).Our results in agreement with all the authors that found Vitek give reliable, rapid and higher correct identification rate[12].

\section{Conclusion}

The results of the present study clearly showed that $S$.aureus is a major cause of mastitis in dairy farm and its incidence was high in clinical mastitis (50\%) than subclinial mastitic cows (17.5\%). All S. aureus isolates in this study showed that symmetrically of the phenotypic characters. The presence of S.aureus in apparently normal milk (subclinical mastitis )cow milk is a potential health hazard. Also that sanitary measures are needed to improve the hygienic conditions during milking

Table (1) Incidence of Staphylococcus aureus in the mastitis cows

\begin{tabular}{llccc} 
Animal case & no. & no. of quarter & \multicolumn{2}{c}{ S.aureus isolates } \\
& & & No & $\%$ \\
\hline Clinically mastitic & 47 & 188 & 39 & 50 \\
Subclinical mastitic & 56 & 224 & 133 & 30.5 \\
Total & 103 & 412 & 30.9 \\
\hline
\end{tabular}

$\underline{\text { Identification of staphylococcus aureus using vitek2 compact system }}$

Identification information Card: GP Lot number:242381940 Expires:May29,201713:CDT

Completed Apr 19,2016 17:40CDT Status :final

Analysis

Time: 4.75 hours

Selected Organism 99\%probability Staphylococcus aureus

Bionumber:10402062763231 Confidence: Excellent identification

\section{References}

[1]A.Kumar, , A.Rahal, S.K.Dwivedi, and M.K.Gupta, Bacterial Prevalence and Antibiotic Resistance Profile from Bovine Mastitis in Mathura, India..J.DairySci., Vol.38, pp.31-34, 2010a

[2]B.A.Tenhagen, I.Hansen, A.Reinecke and W.Heuwieser, Prevalence of pathogens in milk samples of dairy cows with clinical mastitis and in heifers at first parturition. J. Dairy Res., Vol.76, pp.179-187, 2009
[3] S.Piepers, L.De Meulemeester, A.de Kruif, G.Opsomer, H.W.Barkema and S.de Vliegher, Prevalence and distribution of mastitis pathogens in subclinically infected dairy cows inFlanders, Belgium. J. Dairy Res., Vol.74, pp.478-483, 2007

[4] V.D.Bhatt, M.S.Patel, C.G.Joshi and A.Kunjadia, Identification and antibiogram of microbes associated with bovine mastitis. Anim. Biotechnol., Vol.22, pp.163-169, 2011.

[5] D.Cervinkova, H.Vlkova, I.Borodacova, J.M.akovcova and V.Babak etal.Prevalence of 
mastitis pathogens in milk from clinically healthy cows. Vet. Med., 58: 567-575. 2013. Prevalence of mastitis pathogens in milk from clinically healthy cows. Vet. Med., Vol.58, pp.567-575, 2013

[6]S.E. Cramton, C. Gerke, N.F. Schnell, W.W. Nicholsand F. Gotz, The intercellular adhesion (ica) locus in Staphylococcus aureus and is

required for biofilm formation. Infect. Immun., Vol.67, pp.5427-5433, 1999

[7] A.B. Wyder, R. Boss, J. Naskova, T. Kaufmann, A. Steiner, H.U. Graber, Streptococcus spp. and related bacteria: their identification and their pathogenic potential for chronic mastitis - a molecular approach. Res Vet .Sci., Vol.91, pp.349-357, 2011

[8] A. Loonen, A. Jansz, J. Bergland, and P. Wolffs , Comparative study using phenotypic ,genotypic and proteomic methods for identification of coagulase negative staphylococci. J. Clin. Microbiol., Vol.50, pp.1437-1439, 2012

[9] M. C. Rowlinson, P. LeBourgeois, K.Ward, Y. Song, S. M. Finegold, D. A. Bricker isolation of strictly anerobic strains of staphylococcus epidermidis. J. Clin.Microbial., Vol.44(3), pp.857-860, 2006

[10] Biomerieux, Vitek 2 product information document 510769-4EN1. Biomerieux ,INC., Durham NC, 2006

[11] G. Funke and K. Funke, Performance of the New VITEK 2 GP Card for Identification of Medically Relevant Gram-Positive Cocci in a Routine Clinical Laboratory. J. Clin. Microbiol., Vol.43(1), pp.84-88, 2005

[12] K. S. Chatzigeorgiou, T. N. Sergentanis, S.Tsiodras, S. J. Hamodrakas, P.G.Bagos,. Phoenix 100 versus Vitek 2 in the identification of gram-positive and gram-negative bacteria: a comprehensive meta-analysis. Journal of clinical microbiology Vol.49, pp.3284-3291, 2011

[13] P.J.Quinn, B.K.Makey, M.E.Carter, W.J.Donnelly and F.C.Leonard, Veterinary Microbiology and Microbial Diseases. Blackwell Science Ltd, 2002

[14] O.M.Rasositis, D.C.Blood, C.C.Gay, Veterinary Medicine $8^{\text {th }} \mathrm{ed}$ ElBS Bailliere Tiendall London., Sardarkrushinagar, 1994

[15] O.W.Schalm, G.Carroll, and N.C.Jain, Bovine Mastitis. Lea and Fibiger, Philadelphia, USA.,Pages, p.360, 1971

[16]G.I.Barrow and R.K.A Feltham, Cow an and Steel's Manual for the Identification of Medical acteria.3rdEdn.,Cambridge University Press,Cambridge, pp.140-43, 1993.

[17]M.J.Islam, M.S.Uddin, M.A.Islam, Nazir KHMNH, M.T.Rahman, M.M.Alam , Detection and characterization of coagulase-positive Staphylococcus aureusof bovine origin

producing enterotoxins and toxic shock
syndrome toxin-1. The Bangladesh Veterinarians, Vol.24, pp.27-33, 2007b

[18]H.A.Begum, M.S.Uddin, M.J.Islam, Nazir KHMNH, M.A.Islam, M.T.Rahman , Detection of biofilm producing coagulase positive Staphylococcus aureusfrom bovine mastitis, their pigment production, hemolytic activity and antibiotic sensitivity pattern. Journal of the Bangladesh Society for Agricultural Science and Technology, Vol.4, pp.97-100, 2007

[19] M.J.Islam, M.S.Uddin, M.S.Nasrin, Nazir KHMNH, M.T.Rahman, M.M.Alam , Prevalence ofenterotoxigenic and toxic shock syndrome toxin-1 producing coagulase positive Staphylococcus aureusin human and their characterization. Bangladesh Journal of Veterinary Medicine, Vol.5, pp.115-119, 2007a

[20] M.Jahan, M.Rahman, M.S.Parvej, S.M.Z.HChowdhury, M.E.Haque,

M.A.K.Talukder, , S.Ahmed, Isolation and characterization of Staphylococcus aureusfrom raw cow milk in Bangladesh. Journal of Advanced Veterinary and Animal Research, Vol.2, pp.49-55, 2015

[21] J. R.Roberson, L.K.Fox, D.D.Hancock, and T.E.Besser, Evaluation of methods for the differentiation of coagulase-positive staphylococci. J. Clin. Microbiol., Vol.30, pp.3217-3219, 1992

[22] Taylor and L.L.C.Francis Group, International Standard Book Printed in the United States of America Number, Vol.13, pp. 978-1-4398-04087, 2010

[23] J.H.Purohit, Isolation and characteristics of Staphylococcus aureus from bovine milk.Ph.D.Thesis, Gujarat AgriculturalUniversity, 1990

[24] A.Z.Mengistie, Molecular Epidemiology of Staphylococcus aureus and Streptococcus Agalactiae Isolated from Bovine Mastitis in Ethiopia. Mensch and Buch- Verlag,USA., ISBN:9783898205122,Pages, p.139, 2003

[25]F.M.Kivaria, J.P.T.M.Noordhuizen, A.M. Kapaga and H.Hogeveen, Risk indicators associated with Staphylococcus aureus subclinical mastitis in small holder dairy cows in Tanzania. Proceeding $s$ of the4th IDF International Mastitis Conference,June1215,2005, Maastricht ,The Netherlands, pp.722727,2005

[26] R.Ranjan, M.K.Gupta and K.K.Singh, Study of bovine mastitis in different climatic conditions in Jharkh and,India.Vet.World, Vol.4, pp.205208, 2011

[27] Thennarrasu, A.M.R.Muralidharan and M.Murugan, Incidence o f clinical mastitis in bovines-a study in Chennaicity. Cherion, Vol.32, pp.140-141, 2003 
[28] S.Wani, and M.Bhatt, An epidemiological study on bovine mastitis in Kashmir valley.IndianVet.J., Vol.80, pp.841-844, 2003

[29] N.P.Patel,Determination of virulence factors in Staphylococcus aureus isolated from clinical cases of mastitis in sheep, goats, cattle and buffaloes. M.Sc.Thesis, Sardarkrushinagar Dantiwada Agricultural University, Sardarkrushinagar, 2007

[30] F.C.Tuteja, Studies on mastitis in buffaloes with reference to serum selenium status and control by treating teat canal infections. Ph.D. Thesis ,Chaudhary Charan Singh Haryana Agricultura lUniversity ,Hisar, Haryana, 1999

[31] O.Kaya, , S.Kirkan, M.Gulal, and B .Unal, Identification and antibiotic susceptibility of microbes causing mastitis in dairy cows.Vet.Bull.,Vol.70, pp.290-290, 2000

[32] A.D.Hawari and F.Al-Dabbas, Prevalence and distribution o f mastitis pathogens and their resistance against antimicrobial agents in dairy cows in Jordan .Am.J. Anim.Vet.Sci., Vol.3, pp.36-39, 2008

[33]S.C.Nickerson, Control of heifer mastitis: Antimicrobial treatment-an overview. Vet. Microbiol., Vol.134, pp.128-135, 2009

[34] M.Zutic, I.Cirkovic, L,Pavlovic , J.Zutic, J.Asanin, O. Radanovic and N.Pavlovic, Occurrence of methicillin-resistant Staphylococcus aureus in milk samples from Serbian cows with subclinical mastitis. Afr. J.Microbiol.Res., Vol.6, pp.5887-5889, 2012.
[35] K.Pandya, Incidence of Staphylococcus aureus in cow milk and assessment of characteristics associated with its virulence .M.Sc. Thesis, Gujarat Agricultural University, Sardarkrushinagar, 1991

[36] E.Kato, and T.Kume, Enterotoxigenicity of bovine Staphylococci isolated from California mastitis test-positive milk in Japan.Japanese J.Vet.Res., Vol.28, pp.75-85, 1980

[37]P.Boerlin, , P.Kuhnert, , D.Hussy and M.Sehaellibaum, Methods for identification of Staphylococcus aureus isolates in cases of bovine mastitis.J. Clin.Microbiol., Vol.41, pp.767-771, 2003

[38] A.Zecconi, L.F.Calvinho, and K.L.Fox , Staphylococcus aureus intrammamry infections. IDF Bulletin, Vol.408, pp.1-42, 2006

[39]A.Bedane, G.Kasim, , T.Yohannis, , T.Habtamu, B.Asseged and b.Demelash Study on pervelance and risk factors of bovine mastitis in Borona a pastrol and agro pastoral settings of yabella district, Borana zone, southern Ethiopia America-Ethiopia American -Euraseian, J.Agri.\&Environ.Sci., Vol.12(10), pp.12741281, 2012

[40] D.Scherrer, S.Coti, J.E.Muehlberr, C.Zweife , and R.Stephan, Phenotypic and genotypic characteristics of $S$. aureus isolates from raw bulk - tank milk samples . Veterinary Microbiology .101-101-107, 2004. 